\title{
Reactions to a Female Perpetrator of Neglect and Financial Elder Abuse
}

\author{
Nerina J. Caltabiano, Marie L. Caltabiano \\ Discipline of Psychology, College of Healthcare Sciences, Division of Tropical Health and Medicine, James Cook \\ University, Cairns, Australia \\ Email: Nerina.Caltabiano@jcu.edu.au
}

Received 13 March 2016; accepted 31 May 2016; published 3 June 2016

Copyright (C) 2016 by authors and Scientific Research Publishing Inc.

This work is licensed under the Creative Commons Attribution International License (CC BY).

http://creativecommons.org/licenses/by/4.0/

c) (i) Open Access

\begin{abstract}
There is a paucity of Australian research on elder abuse perpetrated by carers. Knowing how individuals would respond to an elder abuse scenario can inform prevention and intervention strategies. The objective of this study was to determine how undergraduate university students enrolled in caring profession degrees respond to an elder abuse scenario. The design of the study involved a paper-and-pencil survey using an elder abuse scenario. Thirty-two undergraduate volunteer students enrolled in a regional university participated in the study. Confronted with the scenario, students would offer the elder physical support such as house cleaning, they would recommend that the elder access government welfare agencies, and consider moving to elder accommodation. They would recommend that the carer get a job, clean the house and call tradespeople. Students enrolled in caring profession degrees, irrespective of gender, were prepared to take actions to improve the welfare of the abuse victim.
\end{abstract}

\section{Keywords}

Elder Abuse, Carers, Financial Abuse, Neglect

\section{Introduction}

Increased longevity is occurring in many countries as a result of medical advances. As the baby boomers move into old age, some will require care due to ill-health and frailty, and may also experience abuse and neglect from their carers.

The Position Statement on Elder Abuse by the Australian Society for Geriatric Medicine (Kurrle, 2004) defined elder abuse as "any pattern of behaviour which causes physical, psychological or financial harm to an older person” (p. 38). Neglect of basic needs such as food, clothing, shelter, hygiene and medical care are also considered 
abuse (Kurrle, 2004). Elder abuse involves a "betrayal of trust” within a relationship, with the recipient of the abuse knowing the perpetrator who may be a partner, family member, neighbour or professional carer (McBride, 2011). A myriad of reasons give rise to the abusive circumstances including carer stress, inadequate care due to the carer's own age or health status, mental health of carer, lack of finances, history of violence or not sharing a previous close-relationship with the person in their care, and cognitive or physical impairment in the elder (Dong, 2015).

Unfortunately, abuse is often not reported to authorities for fear of retribution from the carer, and as such prevalence rates are likely to be an underestimation. Prevalence statistics are also hampered by the heterogeneity in definitions of elder abuse and in assessment instruments across studies (Dong, 2015). Reported prevalence rates for identified cases of elder abuse referred to Aged Care Assessment Teams in Australia range from 2.3\% to 5.4\% (Kurrle, Sadler, \& Cameron, 1992; Kurrle, Sadler, Lockwood, \& Cameron, 1997; Livermore, Bunt, \& Biscan, 2001). In an Australian community survey (Cripps, 2000), 2.7\% of older persons reported abuse, the most common being psychological, followed by financial and physical abuse. In another Australian study (Boldy, Homer, Crouchley, Davey, \& Boylen, 2005), older women were more likely to suffer abuse compared to men, with financial abuse perpetrated by children and other family members being the most common type of abuse.

Some research has focused on perceptions of elder abuse as this has implications for detecting, reporting and responding to abuse. Differences have been found in perceptions of abuse between general practitioners and older adults (Helmes \& Cuevas, 2007) with older adults perceiving scenarios as more severe. Differences have also been reported between health professionals and students in the types of behaviours considered abusive, students perceiving restraining of elders as abusive (Dow, Hempton, Cortes-Simonet, et al., 2013). Females are more likely than males to perceive sexual abuse scenarios as more severe (Helmes \& Cuevas, 2007).

While much of the research has focused on perceptions of elder abuse, less attention has centered on responses to abuse. In a study by Knight, Kim, Rastegar, Jones, Jump, and Wong (2016) which assessed perceptions of financial elder abuse using vignettes, females were less inclined to report financial abuse of elders which might jeopardize the relationship between carer and elder. Whether there are gender differences in responding to abuse situations of other types remains under-studied. A recent systematic review of studies on elder abuse (Dong, 2015) noted the paucity of Australian research on elder abuse.

The aim of this paper was to determine whether students enrolled in caring profession degrees (like Psychology, Social Work, Nursing) who in their later professional capacities may be working with older people, would recognize an abusive situation, and what they would be prepared to do to alleviate it. Also of interest is whether males and females would react in the same way.

\section{Method}

\subsection{Design}

The study used a paper-and-pencil survey to elicit qualitative responses from a sample of volunteer undergraduate students enrolled in caring profession degrees in a regional university.

\subsection{Respondents}

A total of 32 undergraduate university students provided responses to the survey. The age range was 17 to 57 years $(M=29.2$ years, $S D=12.3)$. There were 12 males $(M=36$ years, $S D=15.0$ years $)$ and 20 females $(M=$ 25.2 years, $S D=8.4$ years). The majority of students were Australian $(\mathrm{n}=23,71.9 \%), 17(53.1 \%)$ were employed and studying, and one student was also a carer.

\subsection{The Scenario}

Mr. G. and his 56-year-old unemployed daughter were inspired by a case of reported elder abuse in the American media (Pulley, 2005). Given that the more likely abuse scenario tends to be that of a female victim and male perpetrator, it became pertinent to consider respondent reactions to a reverse scenario, that is, a male victim and a female perpetrator. The scenario also addresses two forms of abuse, namely, financial and neglect.

Mr. G \& Daughter-Mr. G is an 86-year-old widower who lives with his 56-year-old daughter in his own home. His daughter has not worked for the past 16 years but pays the bills by signing her father's name on an 
account where her father's pension is deposited. The father has arthritis, is bed-ridden and spends his day in a stench-ridden house packed with clutter, rubbish and clothes. The plumbing is in need of repair. The bathroomsink overflows with rubbish and debris. Rotting food, cockroaches and spiders are in the house. The daughter believes she is attending to her father's daily needs.

Respondents were asked to give written answers to four questions:

1) What would you do?

2) Who would you recommend the elder contact?

3) What would you recommend the carer/relative do?

4) What would you suggest as a viable alternative form of care?

\section{Results}

Content analysis was used to summarize the students' responses to the four questions. Such a method provides an objective evaluation of content. The final category list and the two rater inconsistencies were resolved via consensus. Students could provide several responses. Table 1 presents the responses given to the four questions for the total sample and split for male and female students, along with the percentage providing each response.

Table 1. Frequency distributions for the open-ended questions for the total sample and split by gender.

\begin{tabular}{|c|c|c|c|c|c|}
\hline \multirow{2}{*}{ Claimed Behaviour } & $\begin{array}{c}\text { Total Sample } \\
\mathrm{n}=32\end{array}$ & \multicolumn{2}{|c|}{$\begin{array}{l}\text { Male Respondents } \\
\mathrm{n}=12\end{array}$} & \multicolumn{2}{|c|}{$\begin{array}{l}\text { Female Respondents } \\
\qquad \mathrm{n}=20\end{array}$} \\
\hline & $\%$ & $\mathrm{n}$ & $\%$ & $\mathrm{n}$ & $\%$ \\
\hline
\end{tabular}

What would you do?

1) Offer the elder physical support - help with the cleaning

2) Seek further information from the elder regarding his needs and history of abuse

3) Investigate the carer and threaten her with legal action

4) Offer carer support and advice

5) Organize welfare services

6) Take no action

\begin{tabular}{|c|c|c|c|c|c|}
\hline 5 & 15.6 & 3 & 25 & 2 & 10 \\
\hline 3 & 9.4 & 2 & 16.7 & 1 & 5 \\
\hline 2 & 6.3 & 0 & 0 & 2 & 10 \\
\hline 2 & 6.3 & 1 & 8.3 & 1 & 5 \\
\hline 4 & 12.5 & 2 & 16.6 & 2 & 10 \\
\hline 4 & 12.5 & 3 & 25 & 1 & 5 \\
\hline 9 & 28.1 & 3 & 25 & 6 & 30 \\
\hline 6 & 18.8 & 1 & 8.3 & 5 & 25 \\
\hline 3 & 9.4 & 2 & 16.7 & 1 & 5 \\
\hline 3 & 9.4 & 2 & 17.6 & 1 & 5 \\
\hline 2 & 6.3 & 2 & 16.7 & 0 & 0 \\
\hline 5 & 15.6 & 1 & 8.3 & 4 & 20 \\
\hline 5 & 15.6 & 1 & 8.3 & 4 & 20 \\
\hline 5 & 15.6 & 2 & 16.7 & 3 & 15 \\
\hline 3 & 9.4 & 0 & 0 & 3 & 15 \\
\hline 8 & 25 & 3 & 25 & 5 & 25 \\
\hline 6 & 18.8 & 2 & 16.7 & 4 & 20 \\
\hline 2 & 6.3 & 2 & 16.7 & 0 & 0 \\
\hline
\end{tabular}

Who would you recommend the elder contact?

1) Access government welfare agencies

2) Community support services e.g. Blue Care

3) Contact government financial agencies

4) Contact aged care residences

5) Talk with the carer

What would you recommend the carer/relative do?

1) Carer get a job

2) Carer clean the house and call tradespeople

3) Seek community support services e.g. Meals on Wheels

4) Seek in-home professional support from agencies e.g. Blue Care

What would you suggest as a viable alternative form of care?

1) Elder move to a specialist home

2) Other family members help with caring responsibilities

3) Seek community support services e.g. Meals on Wheels 


\section{Discussion}

The present study sought to ascertain student responses to an elder abuse scenario involving neglect and financial abuse. Many of the suggested responses were consistent with the options for intervention recommended by the Australian Society for Geriatric Medicine Position Statement (Kurrle, 2004), namely crisis care, provision of community support services, provision of respite, counseling, permanent alternative accommodation and legal intervention. For instance, provision of community support services in the form of meals-on-wheels and home nursing (Blue Nurses) was suggested by the students. Female respondents suggested legal intervention in the form of reporting the daughter for her neglectful behaviour, most likely because it contravened socialization practices for females to be caring towards family members. While counseling was not mentioned as such, males would talk to the elder to assess needs and history of abuse, consistent with management recommendations (Dong, 2015; Fox, 2012). Support for the carer in the form of respite or individual counseling was also mentioned. Both males and females suggested placement in alternative accommodation where specialist care could be provided to the elder. However, female respondents thought that other family members should help with care as an option before removal of the elder from the home. This is consistent with research (Knight et al., 2016) which found that females were more reluctant to disrupt the relationship between carer and elder by reporting financial abuse.

\subsection{Conclusion}

This study provided some indication that students were able to recognize an elder abuse situation and were prepared to take some action whether it be reporting the abuser, providing direct assistance, or suggesting removal of the elder from the home. Whether self-reported behaviour will translate into actual behaviour if confronted with an elder abuse situation remains unknown, but the indications are promising and consistent with recommended actions in the literature for prevention and management of elder abuse.

\subsection{Key Points}

- Students can recognize elder abuse.

- Students would respond to the abuse in ways consistent with recommendations by the Australian Society for Geriatric Medicine Position Statement, namely crisis care, provision of community support services, provision of respite, counseling, permanent alternative accommodation and legal intervention.

- Males and females respond differently to perceived elder abuse.

\section{References}

Boldy, D., Homer, B., Crouchley, K., Davey, M., \& Boylen, S. (2005). Addressing Elder Abuse: Western Australian Case Study. Australasian Journal on Ageing, 24, 3-8. http://dx.doi.org/10.1111/j.1741-6612.2005.00058.x

Cripps, D. (2000). Australia's First Randomised Study of the Prevalence and Effects of Elder Abuse in the General Community. Proceedings of the Australian Association of Gerontology Conference, Adelaide, 25-27 October 2000.

Dong, X. Q. (2015). Elder Abuse: Systematic Review and Implications for Practice. Journal of the American Geriatrics Society, 63, 1214-1238. http://dx.doi.org/10.1111/jgs.13454

Dow, B., Hempton, C., Cortes-Simonet, E. N., Ellis, K. A., Koch, S. H., LoGiudice, D., Mastwyk, M., Livingston, G., Cooper, C., \& Ames, D. (2013). Health Professionals' and Students' Perceptions of Elder Abuse. Australasian Journal on Ageing, 32, 48-51. http://dx.doi.org/10.1111/j.1741-6612.2012.00643.x

Fox, A. W. (2012). Elder Abuse. Medicine, Science and the Law, 52, 128-136. http://dx.doi.org/10.1258/msl.2011.011124

Helmes, E., \& Cuevas, M. (2007). Perceptions of Elder Abuse among Australian Older Adults and General Practitioners. Australasian Journal on Ageing, 26, 120-124. http://dx.doi.org/10.1111/j.1741-6612.2007.00235.X

Knight, B. G., Kim, S., Rastegar, S., Jones, S., Jump, V., \& Wong, S. (2016). Influences on the Perception of Elder Financial Abuse among Older Adults in Southern California. International Psychogeriatrics, 28, 163-169.

http://dx.doi.org/10.1017/S1041610215000587

Kurrle, S. (2004). Elder Abuse. Australian Society for Geriatric Medicine Position Statement No.1. Australasian Journal on Ageing, 23, 38-41. http://dx.doi.org/10.1111/j.1741-6612.2004.00009.x

Kurrle, S., Sadler, P., \& Cameron, I. (1992). Patterns of Elder Abuse. Medical Journal of Australia, 157, 673-676. 
Kurrle, S., Sadler, P., Lockwood, K., \& Cameron, I. D. (1997). Elder Abuse: A Multicentre Australian Study. Medical Journal of Australia, 166, 119-122.

Livermore, P., Bunt, R., \& Biscan, K. (2001). Elder Abuse among Clients and Carers Referred to the Central Coast ACAT: A Descriptive Analysis. Australasian Journal on Ageing, 20, 41-47. http://dx.doi.org/10.1111/j.1741-6612.2001.tb00348.x

McBride, K. (2011). Elder Abuse. InnovAiT, 4, 353-359. http://dx.doi.org/10.1093/innovait/inr062

Pulley, R. (2005). Elder Abuse Charges Filed against Daughter. Knight Ridder Tribune Business News, Washington, 27 January 2005, 1. 